\title{
THE GROWTH OF BONDS AND THE INCREASE OF MECHANICAL STRENGTH IN A DRY SEASONAL SNOW-PACK
}

\author{
By Charles M. Keeler \\ (U.S. Army Cold Regions Research and Engineering Laboratory, \\ Hanover, New Hampshire 03755, U.S.A.)
}

\begin{abstract}
Simultaneous measurements were made of both the strength and structural properties of a dry, seasonal snow-pack. The densities of the snow studied ranged from 126 to $407 \mathrm{~kg} \mathrm{~m}^{-3}$. The mechanical strength of this snow as determined by in situ shear-wave test and a centrifugal tensile test increases exponentially with the increase in size of intergranular sands. Bonding increases at a rate substantially greater than that predicted by the classical sintering equations. It is suggested that this is due to the wide variety of stresses present in snow with these relatively low densities.
\end{abstract}

RÉsumé. La croissance de liens et l'augmentation de la résistance mécanique dans une couche saisonnière sèche. Des mesures simultanées furent effectuées à la fois des propriétés de résistance et de structure d'une couche de neige saisonnière sèche. Les densités de la neige étudiées étaient comprises entre 126 et $407 \mathrm{~kg} \mathrm{~m}^{-3}$. La résistance mécanique de cette neige déterminée par test d'onde de cisaillement et un test de tension centrifuge, croît d'une manière exponentielle avec l'augmentation de la taille des liasons intergranulaires. Les liens de cohésions augmentent d'une quantité supérieure à celle prévue par les équations classiques de tassement. Il est suggéré que cela est dû à la large variété de contraintes de relativités présentes dans la neige à faibles densités.

Zusammenfassung. Das Wachstum von Brücken und die Zunahme der mechanischen Festigkeit in einer trockenen jahreszeitlichen Schneedecke. Es wurden gleichzeitige Messungen der Festigkeit und der strukturellen Eigenschaften in einer trockenen, jahreszeitlichen Schneedecke durchgeführt. Die Dichte des untersuchten Schnees reichte von 126 bis $407 \mathrm{~kg} \mathrm{~m}^{-3}$. Die mechanische Festigkeit dieses Schnees, die durch eine Scherwellenuntersuchung in situ und durch eine zentrifugale Dehnungsuntersuchung bestimmt wurde, wächst exponentiell mit der Grössenzunahme der Brücken zwischen den Körnern. Die Bindung nimmt mit einer Geschwindigkeit zu, die deutlich grösser ist als die durch die klassischen Sinterungsgleichungen vorausgesagte. Es wird vermutet, dass dies auf die grosse Variationsbreite der in Schnee mit so relativ geringer Dichte vorhandenen Spannungen zurückzuführen ist.

\section{INTRODUCTION}

The rate of change in mechanical strength of a snow cover is a parameter of considerable usefulness in glaciological engineering. Intuitively we all recognize that it is a function of the rate of bond growth between individual ice grains which, with their complementary pore spaces, comprise a snow-pack. Unfortunately, the extreme fragility and thermal instability of low density seasonal snow makes the study of bonding extremely difficult.

Studies of the nature of the intergranular bond in snow have been conducted in a laboratory environment (Hobbs and Mason, 1964) and both field and laboratory studies have investigated the strength changes in snow (Ramseier and Sander, I966; Ramseier and Keeler, I966). This paper describes simultaneous measurements on both strength and bonding in a natural, dry, seasonal snow cover, made during the winter of I 966 at Alta, Utah.

\section{Field Methods}

\section{Strength properties}

Brittle fracture stress was measured using shear boxes, shear vanes and a centrifugal tensile apparatus, all of which are fully described in Keeler and Weeks (1968). Whether or not brittle behavior is a correct assumption in all cases is conjectural, but in any event the measured values provide suitable indices for correlation with other snow properties. The effect of temperature has not been considered in the analysis of these data. It is recognized that this is a fundamental weakness of this study, however, in a field situation, temperature variations are not systematic. In any case, the range of temperatures encountered were rather limited, being between $-5^{\circ} \mathrm{C}$ and $-10^{\circ} \mathrm{C}$. 
Figure $\mathrm{I}$ is a plot of shear-vane failure stress versus porosity and density. The open circles represent data obtained from a snow with high densities but low cohesion. These data typify the depth-hoar layers of these snow-packs which, from the standpoint of snow-slope stability, represent very important exceptions to most strength-density relationships. The laboratory data is from direct shear tests conducted by Ballard and others (1965). Unfortunately, these were the only two points in the appropriate density range.

The data were fitted by an expression derived theoretically by Ballard and Feldt (ig66):

$$
\sigma_{\mathrm{f}}=\sigma_{\mathrm{i}} \exp [-2 n /(\mathrm{I}-n)]
$$

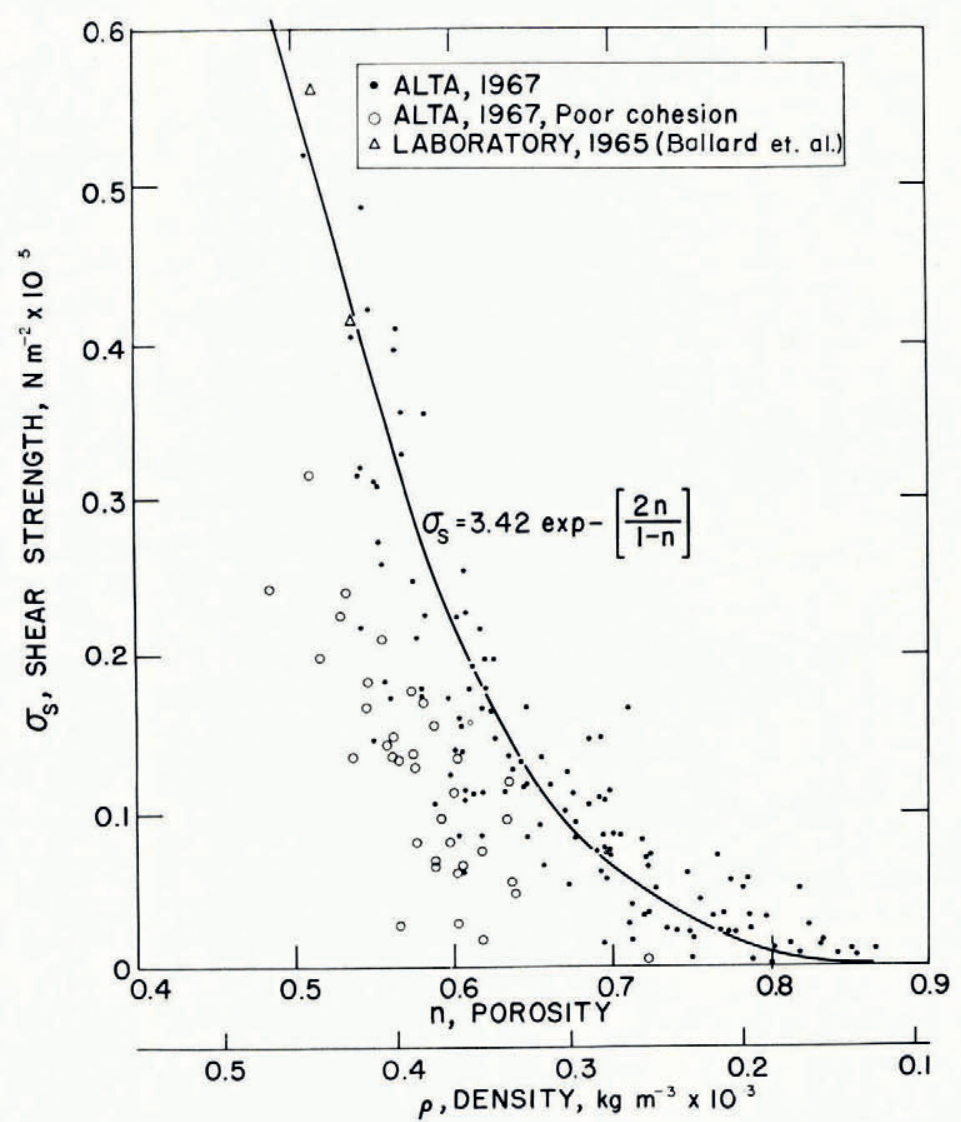

Fig. I. Shear-vane shear strength $\left(\mathrm{Nm}^{-2}\right)$ versus porosity. Only data labeled Alta 1967 (closed dots) has been included in the regression analysis.

where $\sigma_{\mathrm{f}}$ is the failure strength of the sample, $\sigma_{\mathrm{i}}$ is the strength (for the same test procedure) of bubble-free polycrystalline ice with a random crystallographic orientation, and $n$ is the porosity. The value of $\sigma_{\mathrm{i}}$ is unknown and obtained by regressing $\sigma_{\mathrm{f}}$ on $\exp [-2 n /(\mathrm{I}-n)]$. In this case $\sigma_{\mathrm{i}}=3.42 \times 10^{5} \mathrm{~N} \mathrm{~m}^{-2}$ with a correlation coefficient of $0.8_{3}$. This value of $\sigma_{\mathrm{i}}$ is approximately $20 \%$ less than the $\sigma_{\mathrm{i}}$ of $4.05 \times 10^{5} \mathrm{~N} \mathrm{~m}^{-2}$ obtained by Keeler and Weeks ( 1968 ) for data from Goose Lake, Montana. Considering the scatter in both sets of data this is considered to be in reasonably close agreement.

Centrifugal tensile test data were fitted with the same expression yielding a value for $\sigma_{\mathrm{i}}$ of $22.14 \times 10^{5} \mathrm{~N} \mathrm{~m}^{-2}$ with a correlation coefficient of 0.86 . By way of comparison $\sigma_{1}$ for tension 
using the Goose Lake data was $27.3 \times 10^{5} \mathrm{~N} \mathrm{~m}^{-2}$ (Keeler and Weeks, I968). The fact that the tensile strength of these snows should exceed their shear strength has been reported on before (Roch, 1966) but has not as yet been explained. It is likely that the methods of testing may be in part responsible, however, the persistence of the difference suggests that it is worth further study.
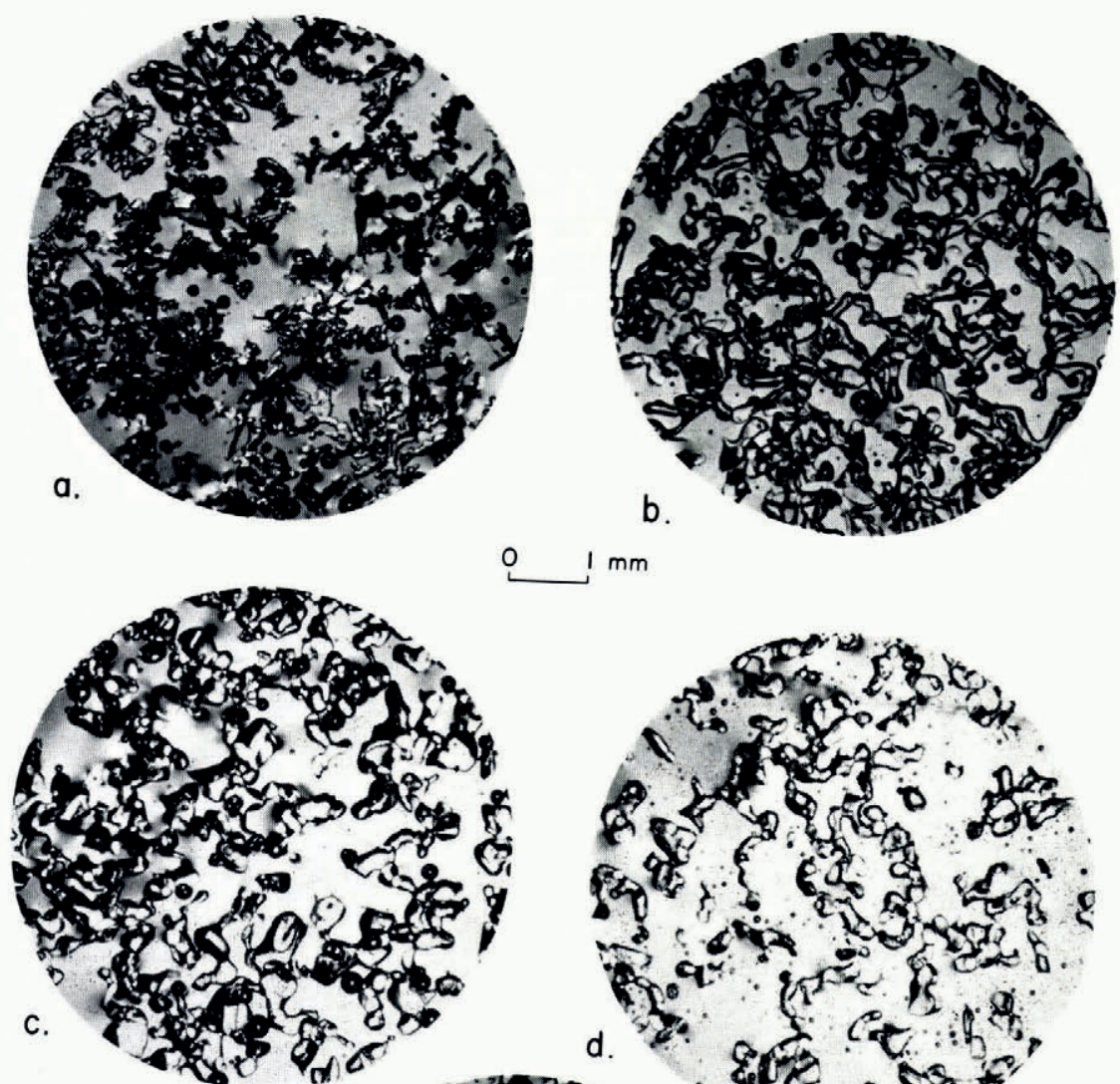

mm 


\section{Structural properties}

Intergranular bonding in snow samples taken in close proximity to the location of the strength measurements (presumably from snow of similar density, age, etc.) was studied in thin sections prepared using the aniline technique. For this purpose a small walk-in freezer was used. Measurements were made on microphotographs similar to those shown in Figure 2.

The absolute accuracy of linear measurements made on such photographs is limited by a number of factors. First, when very porous, poorly cohesive snow is impregnated with aniline, the forces created by the movement of the liquid through the snow tend to destroy whatever tenuous bonding exists. Second, it is very difficult, if not impossible, to section a sample consisting largely of voids and irregularly shaped grains lying in various planes in such a manner that the section yields accurate values of grain dimensions. The problem is complex enough for aggregates of randomly packed unbonded spherical particles (Krumbein and Pettijohn, 1938). As proof of probable errors is the fact that "two-dimensional" densities determined by point count on the photographs differed by a factor of from 1.8 to 2 from the bulk density determination on the same sample. The "two-dimensional" density was always the larger value indicating an overly thick thin section despite the fact that the section was presumably microtomed to approximately one-half the average grain size as previously determined by sieve analysis. This error has been previously discussed by Nakaya and Kuroiwa (1967) who found that for Greenland snow, a $0.3 \mathrm{~mm}$ difference in thin-section thickness could result in a two-dimensional density difference from the bulk density of a factor of 2. The achievement of identical densities using both bulk and thin-section techniques would appear fortuitous. Fortunately, however, the difference between the two values for the Alta samples was constant from section to section (within $10 \%$ ) because the section thickness was not kept the same but was varied as the average grain size of the sample varied. Therefore, the data can be used to show rates of change despite the fact that the absolute values may not be correct.

The data taken from the photographs were:

I. joint order: the number of intersections of lines halving connecting grains (Yosida, ig63);

2. bond diameter: the width of bonds connecting grains;

3. number of bonds per grain.

The data were averaged for each thin section. Thin-section studies were made of samples collected at various depths in a single snow pit (Table I) and at successive time intervals on a stratigraphically identifiable layer (Table II).

The data from Table I can also be used to study the time rate of change of these parameters by assuming that each layer had somewhat similar initial properties and determining the interval from the time of deposition for each depth increment. In other words, time can be substituted for depth if the accumulation rate is known.

Table I. Thin-section Data. Errors where Indicated are Determined by the Distribution of $t=\bar{x}-u / b \bar{x}$ AT THE $95 \%$ Confidence Level

\begin{tabular}{|c|c|c|c|c|c|c|}
\hline Section & Date & $\begin{array}{c}\text { Depth } \\
\mathrm{m}\end{array}$ & $\begin{array}{c}\text { Bulk } \\
\text { density } \\
\mathrm{kg} \mathrm{m}^{-3}\end{array}$ & $\begin{array}{l}\text { Joint } \\
\text { order }\end{array}$ & $\begin{array}{l}\text { Bond diameter } \\
\mathrm{mm}\end{array}$ & $\begin{array}{l}\text { Bonds per } \\
\text { grain }\end{array}$ \\
\hline c & 5 March & 0.15 & 225 & 3.18 & 0.029 & 0.85 \\
\hline d & 5 March & 0.30 & 289 & 3.09 & 0.039 & I. 34 \\
\hline $\mathrm{e}$ & 5 March & 0.40 & 296 & $3 \cdot 36$ & 0.032 & 1.28 \\
\hline e & $5 \mathrm{March}$ & 0.40 & 296 & $3 \cdot 3^{2}$ & $0.034 \pm 0.001$ & $1.35 \pm 0.15$ \\
\hline$f$ & 5 March & 0.58 & 370 & $3 \cdot 33$ & $0.097 \pm 0.002$ & $2.01 \pm 0.3^{2}$ \\
\hline g & 5 March & 0.80 & 3 II & 3.11 & $0.09^{1} \pm 0.003$ & I. $86 \pm 0.26$ \\
\hline $\mathrm{h}$ & 5 March & I. 10 & 406 & 3.40 & $0.107 \pm 0.004$ & $2.87 \pm 0.34$ \\
\hline $\mathrm{i}$ & 3 March & 1.80 & 405 & 3.09 & $0.121 \pm 0.006$ & $2.00 \pm 0.33$ \\
\hline $\mathrm{j}$ & 3 March & $2.5^{\circ}$ & 365 & 3.47 & $0.05^{1} \pm 0.003$ & $\mathrm{I} .37 \pm 0.16$ \\
\hline
\end{tabular}


BOND GROWTH AND STRENGTH INCREASE IN SNOW

Table II. Thin-section Data: Time Studies: Layer of 5 December

\begin{tabular}{|c|c|c|c|c|c|}
\hline Date & $\begin{array}{c}\text { Elapsed } \\
\text { time }\end{array}$ & $\begin{array}{c}\text { Bulk } \\
\text { density }\end{array}$ & $\begin{array}{c}\text { Bond } \\
\text { diameter }\end{array}$ & $\begin{array}{l}\text { Bonds per } \\
\quad \text { grain }\end{array}$ & $\begin{array}{c}\text { Grain } \\
\text { diameter }\end{array}$ \\
\hline & $\mathrm{d}$ & $\mathrm{kg} \mathrm{m}^{-3}$ & $\mathrm{~mm}$ & & $\mathrm{~mm}$ \\
\hline 7 December & 2 & 126 & 0.010 & 0.60 & $0.3^{8}$ \\
\hline I8 December & I3 & 229 & 0.046 & I. $2 \mathrm{I}$ & 0.40 \\
\hline 2 February & 59 & 238 & $0.1 \mathrm{I} \pm 0.009$ & 2.45 & $0.4^{6}$ \\
\hline 9 February & 66 & 343 & $0.122 \pm 0.011$ & 2.08 & 0.45 \\
\hline I3 February & 70 & 377 & $0.119 \pm 0.010$ & 2.68 & $0.4^{8}$ \\
\hline 20 February & 77 & $3^{85}$ & $0.126 \pm 0.012$ & 2.70 & $0.5^{\mathrm{I}}$ \\
\hline 24 February & $8 \mathrm{I}$ & 378 & $0.13^{2} \pm 0.01 \mathrm{I}$ & 2.72 & 0.54 \\
\hline 28 February & 85 & 388 & $0.130 \pm 0.009$ & 2.71 & 0.54 \\
\hline 3 March & 88 & $3^{87}$ & $0.128 \pm 0.012$ & 2.74 & $0.5 \mathrm{I}$ \\
\hline 5 March & 90 & 407 & $0.137 \pm 0.016$ & 2.83 & 0.60 \\
\hline
\end{tabular}

In Table I two sections at $0.40 \mathrm{~m}$ are included to give some idea of the errors involved in replication. In this case they do not appear large.

The joint order is quite constant. Yosida ( 1963$)$ theorized that this indicates that the basic structure of the network is preserved during metamorphism despite changes in grain and bond sizes. This may well be the case within the limited range of stresses found in a seasonal snow cover. The exception to this is the breakdown of intergranular bonding which occurs during the formation of depth hoar. The mean number of bonds per grain is the measurement least subject to error and consequently a valuable index of structure.

A further parameter calculated from the measured data is bond area per unit area of section. This was calculated from bond diameter and numbers of bonds per unit area of section, using the assumption that the bonds are circular in cross-section and that bonding is spatially uniform (i.e. that thin-section orientation does not affect the number of bonds in the section).

\section{Relationship between Snow Strength and Snow Structure}

While empirical correlations between snow strength and density, grain size, depth, time, etc. are useful as predictors they are rarely explanatory. Ultimately, at constant temperature, snow strength is a direct function of the number and size of intergranular bonds, a fact intuitively recognized by most people and quantitatively described to some extent by Nakaya (1961), Butkovich (r962), Anderson and Benson (r963), Hobbs (r965), Ballard and McGaw (1966), Ramseier and Sander (1966), Ramseier and Keeler (1966), and Ballard and Feldt (i 966$)$.

Figure 3 shows a plot of shear-vane strength versus unit bond area. Ballard and McGaw ( 1966 ) described a failure condition in which failure occurred under uniform stress when bonds were stressed to the ultimate strength of ice, $\sigma_{\mathrm{i}}$. A geometric analysis of the resulting failure surface gave an effective porosity, $n_{\mathrm{f}}$, which is equal to ( $\mathrm{I}$ - unit bond area). $n_{\mathrm{f}}$ generally exceeds the bulk porosity $n$ and does so to the greatest degree in low density (high porosity) snow. Ballard and McGaw consider $n_{\mathrm{f}}$ to be a linear function of bulk porosity $n$, and this agreed well with data for bulk porosity less than $50 \%$.

The data in Figure 3 can be fitted with the expression:

$$
\sigma_{\mathrm{f}}=\sigma_{\mathrm{i}} \exp \left(-0.14 n_{\mathrm{f}}\right)
$$

which is similar in form to Equation ( $\mathrm{I}$ ), the more general expression for strength derived by Ballard and Feldt (I966) for the entire porosity range. $\sigma_{i}$ predicted by Equation (2) is I. $2 \times 10^{5} \mathrm{~N} \mathrm{~m}^{-2}$ which is at least of the same order of magnitude as the value of $3.42 \times 10^{5}$ $\mathrm{N} \mathrm{m}^{-2}$ predicted by Equation ( $\mathrm{I}$ ), which used bulk porosity. This lends credence to the notion that Equation ( $\mathrm{I}$ ) is a workable expression for the strength-density relation for snow over a wide range of densities. 


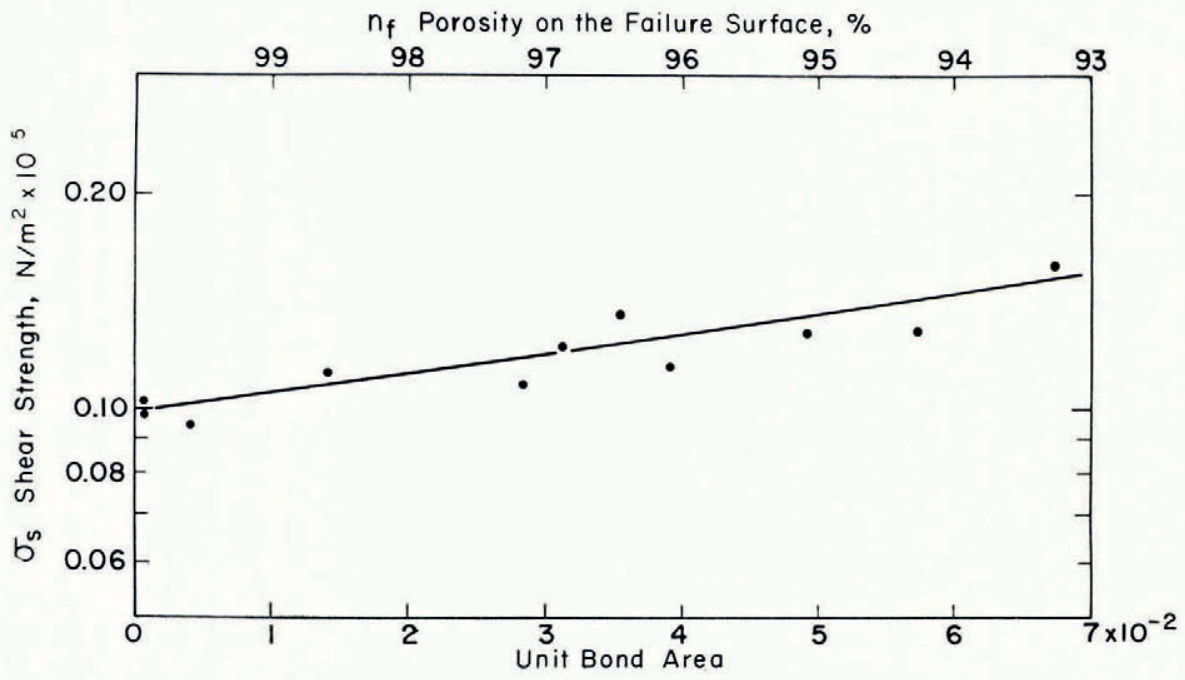

Fig. 3. Shear-vane strength versus unit bond area.

Time Dependence of Strength and Bonding

The classical theory of sintering predicts that bond growth between particles will occur at a rate which may be expressed as

$$
\frac{X}{R}=\frac{f(\mathcal{T}) t^{\mathrm{I} / n}}{R^{m}}
$$

where $X$ is the bond neck radius, $R$ the radius of the particles, $f(T)$ a temperature term, $t$ is time and $n$ and $m$ are constants which depend on the mechanism by which sintering occurs. There is considerable evidence that, at the temperatures normal to most snow-packs, this

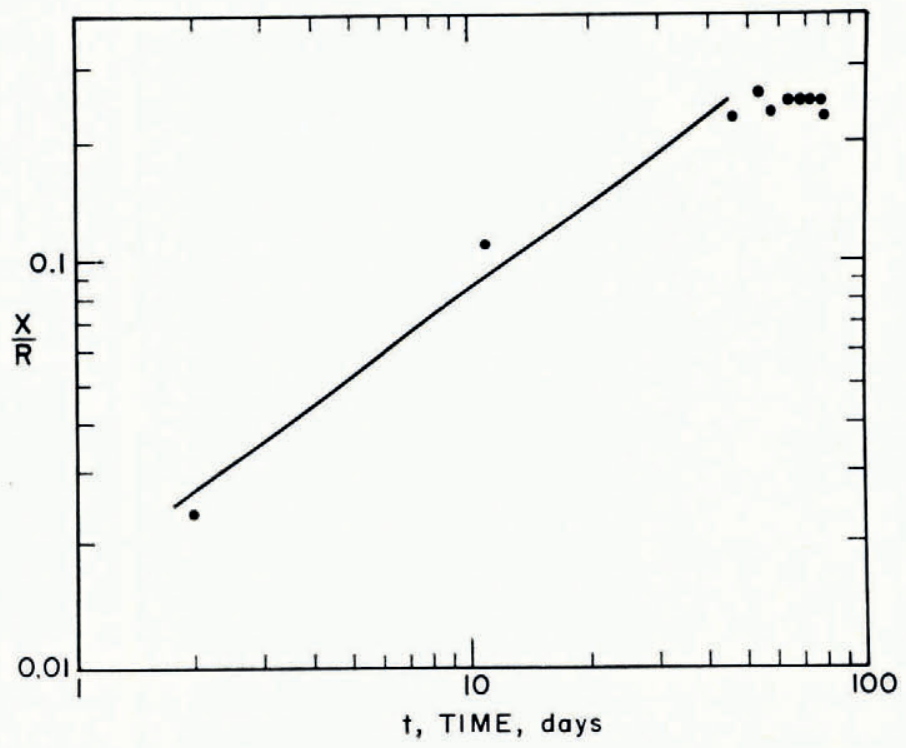

Fig. 4. Ratio of $X$ (bond radius) to $R$ (grain radius) versus time. 
mechanism is one of mass transport by diffusion through the environmental vapor (Hobbs and Mason, I964; Ramseier and Keeler, I966). In this case the value of $n$ should be about 3 (Hobbs and Mason, I964). Most of the experimental work in this field has involved observing the behavior of small ice spheres placed together in a uniform environment. Needless to say, the situation in a snow-pack where there may be gross mass transport in and out of the system and repeated temperature cycling is considerably less amenable to formalization. A plot of the logarithm of $(X / R)$ against the logarithm of time is shown in Figure 4 using the data of bond diameter and grain diameter from Table II. While errors in determining $R$ for irregularly shaped particles must be taken into account, the rising portion of the curve has a slope of 0.75 $(n=\mathrm{I} .3)$. After $47 \mathrm{~d} X$ ceases to increase and the ratio $(X / R)$ decreases slightly due to general grain growth. The significantly higher rate of bond growth than that predicted by the

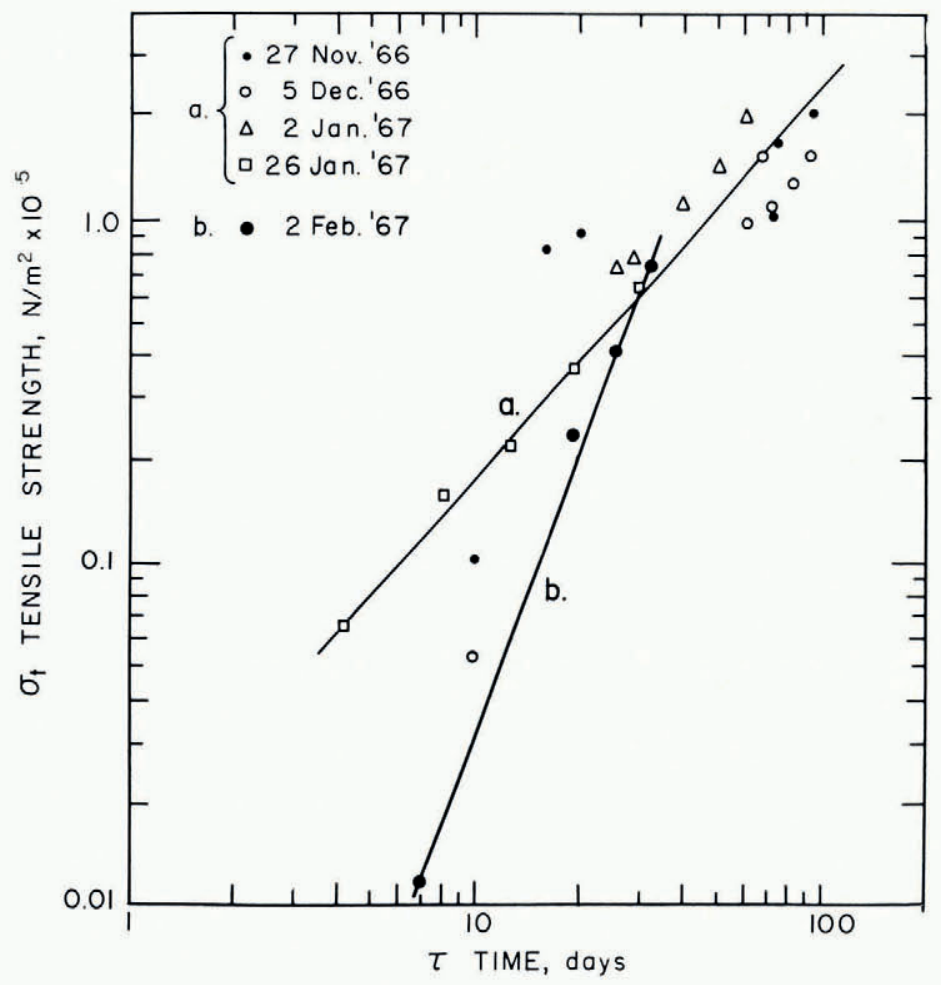

Fig. 5. Centrifugal tensile strength versus time for .5 selected snow layers (dates refer to date of deposition).

sintering equation may possibly be attributed to convective circulation within the void spaces of the snow-pack, temperature cycling, or viscous creep induced by overburden pressures (the exponent for this particular mechanism should be about 2 (Hobbs and Mason, i 964)). While the overburden pressures are not high for a bulk sample they may impose a considerable absolute stress at points of contact because of the relatively small area of the contact surfaces. It is suggested that the rather static $X / R$ ratio occurring from $47 \mathrm{~d}$ and thereafter indicates that bond growth has reached its limit for snow in this environment. The value of the ratio $(X / R \approx 0.25)$ is approximately that predicted for the initial stages of sintering of powder compacts, i.e. prior to grain growth and pore-shape change (Coble, I96I). To substantiate this, reference should also be made to the constancy of joint order referred to earlier, which suggests that the geometry of pores and solids does not change greatly within this density range. 
Table I indicates that a similar situation exists with respect to the number of bonds per grain. During the initial stages of sintering the snow is being stressed by overburden pressures which push grains together and mechanically increase the number of intergranular contacts. At some point densification has proceeded far enough so that the snow is in equilibrium with the stress imposed upon it. In the absence of greatly increased overburden pressures the mechanical arrangement of grains will not change and at this point there is no tendency to create new bonds.

Figure 5 is a plot of tensile strength against time for various snow layers. These layers were dated stratigraphically using natural and colored-yarn horizons. The plot is on logarithmic paper to accommodate the large changes in both variables. The snow temperatures during this time were between -10 and $-5{ }^{\circ} \mathrm{C}$ and varied many times for each particular layer.

Hobbs (1965) found that for certain sets of strength data a power function of time appeared to give the best fit. He explained this as being due to the fact that strength should be linearly related to bond growth which he also found to be a power function of time. The slopes of his strength versus time curves were of the order of 0.3 to 0.4 whereas those of Figure 5 are 1.2 for curve a and 2.9 for curve b. Regardless of whether a power law represents the physical case or is simply a convenient way of presenting these data, the great disparity in the rates of strengthening deserves comment.

The most notable difference between the data analysed by Hobbs and the Alta data is the density at the start of sintering. Hobbs used data from prepared samples with initial densities of $55^{\circ} \mathrm{kg} \mathrm{m}^{-3}$ (Jellinek, I959), processed snow with densities of 430 to $580 \mathrm{~kg} \mathrm{~m}^{-3}$ (Nakaya, I959), and compacted snow with densities of 350 to $650 \mathrm{~kg} \mathrm{~m}^{-3}$ (Wuori, I963) whereas the Alta snow plotted in Figure 5 has initial densities on the order of $150 \mathrm{~kg} \mathrm{~m}^{-3}$. Furthermore, the Alta snow, under conditions of constantly increasing overburden pressure, was densifying continuously and rapidly. A second obvious difference is the much lower strength of Alta samples. Even less than $\mathrm{I} h$ after the preparation of his samples Jellinek found compressive strengths two orders of magnitude higher than the shear strength of $20 \mathrm{~d}$ old Alta snow (shear and compressive strength are generally considered to be of the same order of magnitude for the same sample (Mellor, r966)).

The most likely explanation for the difference in rate of strengthening between various snow types appears to lie in the nature of the snow itself. It is suggested that the same factors which produce rapid densification in the Alta snow samples produce the rapid increases in strength. Despite the fact that Equation (I) and experimental evidence (see Fig. I) predict a very low dependence of strength on density for low-density samples, new snow with its many irregular and sharply curved surfaces and high surface energies rapidly compacts and strengthens until some semblance of stability is achieved. It is quite likely that rapid fluctuations in temperature play a role in this process (Butkovich, I959). This appears to be substantiated by the higher rate for curve b (Fig. 5) which was for snow existing near the surface under warmer ambient temperatures than any of the other layers plotted.

More fundamental proof of the fact that differences in rates of strengthening are due to snow structure is demonstrated in Figure 6 which is a plot of unit bond area versus time based on the data of Table II. The initial slope of the curve is 3.3 and the second portion has a slope of 0.25 . At the point of discontinuity the snow density is $350 \mathrm{~kg} \mathrm{~m}^{-3}$ at an age of $50 \mathrm{~d}$. A density of $350 \mathrm{~kg} \mathrm{~m}^{-3}$ represents a reasonable level of compaction for the normal overburden pressure in deep, dry alpine snow-packs at their greatest accumulation and at this point the rate of densification is very slow (Keeler, ${ }_{1967}$ ). At this time the $X / R$ ratio (bond diameter to grain diameter) was approximately 0.2 which, as has been discussed, is approximately the ratio which marks the end of the initial period of sintering (neck growth only). Both these facts suggest that this is the point beyond which geometrical relationships will change slowly and grain boundaries have somewhat stabilized. It is, therefore, reasonable to expect that processes related to these changes will likewise be slowed. 


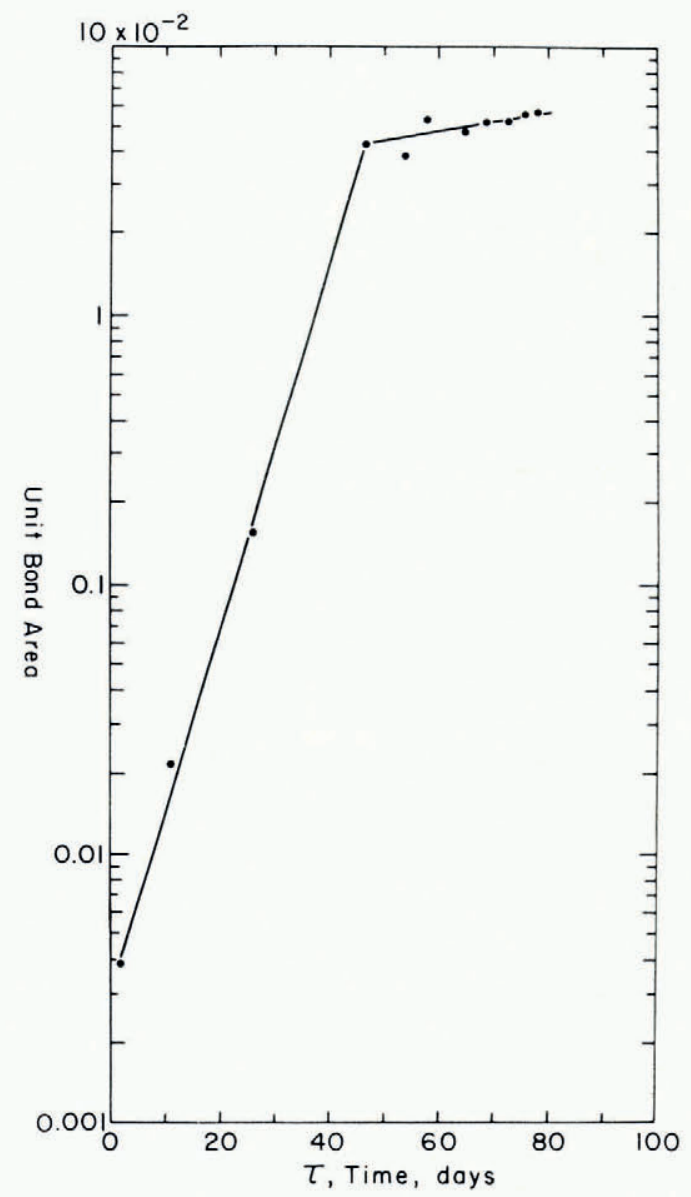

Fig. 6. Unit bond area versus time for data of Table II.

\section{Conclusions}

It would be presumptuous to suggest that a bond growth law can be derived from these data. The interrelation of a number of variables; time, temperature, temperature gradient, and overburden stress is extremely complex in a natural snow pack and there is no way in which their individual effects can be systematically studied.

It is apparent, however, that existing theories, including the classical sintering equations, do not accurately fit the whole range of properties found in natural snow. Both the growth of existing bonds and the creation of new bonds are very much more rapid in low density, new snow than seems to be the case in older, denser snow.

The fact that the relationship between bond size and strength properties agrees reasonably well with relationships derived using macroscopic properties (e.g. bulk density) is encouraging as it indicates that the fundamental assumptions used are correct. If, as suggested, there is a strength-density relationship which is applicable over a broad range of densities then it is likely that other phenomena, including the increase of snow strength with time, can also be described as a continuous process.

MS. received I4 April 1969 and in revised form I9 May 1969 


\section{REFERENGES}

Anderson, D. L., and Benson, C. S. 1963. The densification and diagenesis of snow. (In Kingery, W. D., ed. Ice and snow; properties, processes, and applications: proceedings of a conference held at the Massachusetts Institute of Technology, February $12-16,1962$. Cambridge, Mass., The M.I.T. Press, p. 391-4II.)

Ballard, G. E. H., and Feldt, E. D. 1966. A theoretical consideration of the strength of snow. Fournal of Glaciology, Vol. 6, No. 43, p. I59-7o.

Ballard, G. E. H., and McGaw, R. W. 1966. A theory of snow failure. Union de Géodésie et Géophysique Internationale. Association Internationale d'Hydrologie Scientifique. Commission pour la Neige et la Glace. Division Neige Saisonnière et Avalanches. Symposium international sur les aspects scientifiques des avalanches de neige, 5-10 avril 1965, Davos, Suisse, p. $160-69$.

Ballard, G. E. H., and others. 1965 . Direct shear study on snow, by G. E. H. Ballard, E. D. Feldt and S. R. Toth. U.S. Cold Regions Research and Engineering Laboratory. Special Report 92.

Butkovich, T. R. 1962. Studies of the age hardening of processed snow. U.S. Cold Regions Research and Engineering Laboratory. Research Report 99.

Coble, R. L. 196I. Sintering crystalline solids. I. Intermediate and final state diffusion models. Fournal of Applied Physics, Vol. 32, No. 5, p. 787-92.

Hobbs, P. V. 1965 . The effect of time on the physical properties of deposited snow. Fournal of Geophysical Research, Vol. 7o, No. I6, p. 3903-07.

Hobbs, P. V., and Mason, B. J. 1964. The sintering and adhesion of ice. Philosophical Magazine, Eighth Ser., Vol. 9 , No. 98 , p. $181-97$.

Jellinek, H. H. G. 1959. Compressive strength properties of snow. Journal of Glaciology, Vol. 3, No. 25, p. 345-54.

Keeler, C. M. 1967. Some observations on the densification of alpine snow covers. U.S. Cold Regions Research and Engineering Laboratory. Technical Report 197.

Keeler, C. M., and Weeks, W. F. 1968. Investigations into the mechanical properties of alpine snow-packs. Journal of Glaciology, Vol. 7, No. 5o, p. 253-71.

Krumbein, W. C., and Pettijohn, F. J. 1938. Manual of sedimentary petrography. New York, Appleton Century Crofts, Inc.

Mellor, M. 1966. Snow mechanics. Applied Mechanics Reviews, Vol. 19, No. 5, p. 379-89.

Nakaya, U. 1959. Visco-elastic properties of processed snow. U.S. Snow, Ice and Permafrost Research Establishment. Research Report 58.

Nakaya, U. I96r. Elastic properties of processed snow with reference to its internal structure. U.S. Cold Regions Research and Engineering Laboratory. Research Report 82.

Nakaya, U., and Kuroiwa, D. 1967. Physical properties and internal structure of Greenland snow. (In Oura, H., ed. Physics of snow and ice: international conference on low temperature science. . . . 1966. . . Proceedings, Vol. I, Pt. 2. [Sapporo], Institute of Low Temperature Science, Hokkaido University, p. 953-71.)

Ramseier, R. O., and Keeler, C. M. 1966. The sintering process in snow. Fournal of Glaciology, Vol. 6, No. 45, p. $42 \mathrm{I}-24$.

Ramseier, R. O., and Sander, G. W. 1966. Sintering of snow as a function of temperature. Union de Géodésie et Géophysique Internationale. Association Internationale d'Hydrologie Scientifique. Commission pour la Neige et la Glace. Division Neige Saisonnière et Avalanches. Symposium international sur les aspects scientifiques des avalanches de neige, 5-10 avril 1965 , Davos, Suisse, p. I19-27.

Roch, A. 1966. Les variations de la résistance de le neige. Union de Géodésie et Géophysique Internationale. Association Internationale d'Hydrologie Scientifique. Commission pour la Neige et la Glace. Division Neige Saisonnière et Avalanches. Symposium international sur les aspects scientifiques des avalanches de neige, 5-1o avril 1965, Davos, Suisse, p. 86-99.

Wuori, A. F. 1963. Snow stabilization studies. (In Kingery, W. D., ed. Ice and snow; properties, processes, and applications: proceedings of a conference held at the Massachusetts Institute of Technology, February 12-16, 1962. Cambridge, Mass., The M.I.T. Press, p. 438-58.)

Yosida, Z. I963. Physical properties of snow. (In Kingery, W. D., ed. Ice and snow; properties, processes, and applications: proceedings of a conference held at the Massachusetts Institute of Technology, February 12-16, 1962. Cambridge, Mass., The M.I.T. Press, p. 485-527.) 